\title{
Acumulação de Forragem e Material Morto em Pastagem Nativa sob Distintas Alterna- tivas de Manejo em Relação às Queimadas ${ }^{1}$
}

\author{
Ingrid Heringer ${ }^{2}$, Aino Victor Ávila Jacques ${ }^{3}$
}

\begin{abstract}
RESUMO - Foram estudados cinco sistemas de manejo da pastagem nativa, sob pastejo, do Estado do Rio Grande do Sul: com queima bienal há mais de 100 anos, sem queima há 32 anos com e sem roçada; e melhorado há 7 e 24 anos. O acúmulo de forragem e o material morto desprendido da planta foram coletados em gaiolas de exclusão ao pastejo. O delineamento experimental foi o completamente casualizado com três repetições. Os sistemas sem queima foram mais produtivos, e dentre estes a acumulação de forragem foi semelhante entre sem queima e sem roçada e os tratamentos melhorados com acúmulo anual superior a $9.000 \mathrm{~kg} / \mathrm{ha} \mathrm{de} \mathrm{matéria} \mathrm{seca} \mathrm{da} \mathrm{forragem} \mathrm{verde}$ (MSFV). O material morto presente na superfície do solo foi maior no tratamento sem queima e sem roçada, menor no queimado e intermediário nos demais. Alternativas de manejo sem queima são mais produtivas e ecologicamente mais sustentáveis.
\end{abstract}

Palavras-chave: manejo de pastagem, material morto, pastagem natural, produção, queima

\section{Forage Production and Litter in Native Pasture under Distinct Alternative Management Practices in Relation to Burning}

\begin{abstract}
It was studied five management systems of native pasture, under grazing, from Rio Grande do Sul State: with biennial burning for more than 100 years, without burning for 32 years with or without mowing, and pasture improvement for 7 and 24 years. The forage accumulation and the senescent material detached from the plant, were evaluated using grazing exclusion cage. The experimental design was a completely randomized with three replications. The systems without burning were more productive and among these the forage accumulation was similar among without burning and without mowing and the improvement treatments with annual accumulation higher than $9,000 \mathrm{~kg} /$ ha of green forage dry matter. The litter was higher with treatment without burning and without mowing, lower with burning, and intermediate with other treatments. The alternative management showed to be more productive and more sustainable as compared with burning practices.
\end{abstract}

Key Words: burn, litter, native pasture, pasture management, production

\section{Introdução}

O fogo incide sobre a vegetação desde tempos remotos e é utilizado como ferramenta de manejo na abertura de novas áreas agrícolas, no controle de pragas de pastagens e lavouras, e para eliminar as sobras de pasto envelhecidas. A literatura, no entanto, mostra muita controvérsia em relação aos efeitos do fogo na qualidade, produção e flora das pastagens, bem como sobre as propriedades químicas, físicas e biológicas do solo.

Os efeitos do fogo sobre a produtividade da vegetação são variáveis (Daubenmire, 1968), em função da intensidade e freqüência do distúrbio, e das condições intrínsecas de cada sítio. A produção da pastagem pode aumentar após o fogo diretamente em função da incorporação de cinzas (Kauffman et al., 1994), redução do sombreamento, aumento na disponibilidade de nitrogênio devido à redução de material carbonáceo, e aquecimento do solo (Daubenmire, 1968). De outra maneira, a condição temporária de déficit hídrico, a falta de vigor (Castilhos \& Jacques, 1984) e a perda de fertilidade em locais sujeitos à erosão (Luizão et al., 1993; Giovannini et al., 1990; Giovannini \& Lucchesi, 1997; Hester et al., 1997) podem culminar em decréscimo na produção de forragem em áreas queimadas.

O pequeno impacto das queimadas na produção de matéria seca e na qualidade da forragem, quando comparada ao pastejo ou corte mecânico, é levantado em alguns experimentos (Daubenmire, 1968; Castilhos \& Jacques, 1984; Girardi-Deiro, et al., 1994; Damé et

\footnotetext{
${ }^{1}$ Parte da tese de Doutorado apresentada à Universidade Federal do Rio Grande do Sul pelo primeiro autor. Parcialmente financiado pelo Conselho Nacional de Desenvolvimento Científico e Tecnológico (CNPq).

2 Zootecnista, Dra. Bolsista do CNPq. E.mail: renato@prezzotto.com.br. Rua Coronel Passos Maia, 1103, ap. 103. Xanxerê-SC. CEP: 89.820-000

${ }^{3}$ Engenheiro-Agrônomo, PhD. Professor do Departamento de Plantas Forrageiras e Agrometeorologia, UFRGS. Pesquisador do CNPq E.mail: aino@vortex.ufrgs.br
} 
al., 1997). No entanto, a médio e longo prazo, este distúrbio pode acarretar, direta ou indiretamente, grandes alterações no solo e na vegetação, decorrentes da redução no material morto, cobertura (Castilhos \& Jacques, 1984) e umidade do solo, principalmente quando associado ao pastejo. Pillar \& Quadros (1997) comentam que a falta de maiores efeitos da queima e pastejo sobre a flora da pastagem natural pode indicar estabilidade da vegetação, sugerindo que os campos sulamericanos representam um estado estacionário, dependente de distúrbios, que incluem fogo e pastejo.

Uma série de alternativas podem ser usadas para suprimir o uso do fogo, dentre elas o diferimento, roçada e o melhoramento da pastagem nativa.

O diferimento consiste na exclusão do pastejo por um curto período e pode ser utilizado como reserva de forragem para os períodos de deficiência alimentar, bem como para favorecer o desenvolvimento de espécies. Esta prática ainda auxilia na recuperação de áreas degradadas pelo excesso de pastejo e fogo, em função do acúmulo de matéria orgânica e desenvolvimento radicular (Nabinger, 1980). Além disso, é uma excelente ferramenta de manejo para ajustar as flutuações na oferta de forragem com a carga animal (Nabinger, 1980), sem permitir acúmulo de forragem de baixo valor nutritivo e as subseqüentes queimadas. A exclusão ao pastejo em períodos estratégicos também pode afetar em muito a dinâmica da vegetação (Moojen, 1991).

A roçada, quando usada em época oportuna e com manejo e lotações adequadas, é uma maneira econômica e eficiente de melhorar a pastagem. Para redução das espécies indesejáveis, o momento de roçar deve coincidir com o seu florescimento, quando as reservas forem deslocadas para a produção de sementes.

A utilização de práticas de melhoramento da pastagem natural com correção e adubação do solo e introdução de espécies cultivadas tem favorecido tanto a produção das espécies nativas como das introduzidas, minimizando a deficiência de forragem no período de outono/inverno (Barreto et al.,1978; Silva \& Jacques, 1993). Dentro desse mesmo enfoque, a introdução de leguminosas cultivadas hibernais tem aumentado a qualidade e a produção da pastagem nativa (Barreto et al., 1978; Castilhos \& Jacques, 1984). O aumento na fertilidade dos solos sob pastagem natural visa geralmente a melhorar o ambiente para introdução de espécies cultivadas, mas também contribui para diminuir a participação de gramíneas cespitosas grosseiras, de espécies indesejáveis e de material morto, além de reduzir a superfície de solo descoberto (Moojen, 1991).
O objetivo deste trabalho foi estudar a produção de forragem e de material morto em relação ao efeito de distintas alternativas de manejo da pastagem nativa em comparação às queimadas na região dos Campos de Cima da Serra do Rio Grande do Sul.

\section{Material e Métodos}

Este estudo foi realizado em duas propriedades particulares, localizadas no município de André da Rocha-RS, na região fisiográfica dos Campos de Cima da Serra, a uma altitude aproximada de $800 \mathrm{~m}$, a $28^{\circ} 38^{\prime}$ de latitude sul e $51^{\circ} 34^{\prime}$ de longitude oeste.

O clima da região é temperado úmido $(\mathrm{Cfb})$, segundo classificação de Köeppen, com verões amenos. A temperatura média anual é de $17,6^{\circ} \mathrm{C}$, e a precipitação média anual está entre 1600 e $1700 \mathrm{~mm}$. O solo das áreas estudadas é um Latossolo Vermelho Distroférrico típico (EMBRAPA, 1999), de textura argilosa, pertencente à Unidade de Mapeamento Durox. Caracteriza-se quimicamente pela baixa saturação de bases, deficiência de $\mathrm{P}$, teores altos de matéria orgânica e níveis tóxicos de alumínio.

A vegetação natural pertence à classe "Campos do Brasil Central" representando uma zona de transição entre o campo e a mata, com grande cobertura e dominância de gramíneas cespitosas dos gêneros Aristida, Andropogon, Schizachyrium, Elyonurus e Trachypogon(Burkart, 1975). Anteriormente à adoção de diferentes manejos das áreas, essas pertenciam a uma só propriedade, eram manejadas da mesma forma, apresentando vegetação similar e uniforme, conforme relato dos proprietários.

Realizou-se o estudo sobre cinco áreas de campo nativo, todas pastejadas e manejadas sob distintas formas: sem queima e sem roçada há 32 anos; sem queima há 32 anos e roçada anualmente; melhorada há 7 anos (CNM 7 anos); melhorada há 24 anos (CNM 24 anos); queimada numa freqüência bienal há mais de 100 anos. A queima foi feita a cada dois anos, entre o final do inverno e início da primavera. $\mathrm{Na}$ avaliação dos componentes da vegetação, foram levantados como principais contribuintes na matéria seca disponível no tratamento sem queima e sem roçada: material morto (MM) com 40,0\%, Sorghastrum spp. com 18,6\%, Paspalum notatum Fl. com 11,9\% e Eringium horridum Malme com 10,0\%; no sem queima e com roçada: $P$. notatum com $57,6 \%$, MM com 13,4\%, e Piptochaetium montevidense (Spreng.) Parodi com 6,2\%; no CNM 7 anos: P. notatum com 49,1\% e MM com 15,1\%; no CNM 24 anos: MM 
com $14,3 \%, P$. paniculatum L. com $17,2 \%$ e $P$. notatum com 14,3\%; e no queimado: Piptochaetium montevidense com 24,5\%, MM com 19,3\%, Andropogon selloanus (Hack.) Hack. com 10,6\% e Schizachirium tenerum Nees com 7,7\% (Heringer, 2000).

O delineamento experimental foi completamente casualizado com três repetições.

O solo da área melhorada há 24 anos (CNM 24 anos), em 1973, recebeu preparo convencional, calagem e adubação, seguida de semeadura de aveia (Avena sativa L.) cv. Coronado para produção de sementes. Em 1974 a área foi gradeada, adubada e nela foi semeada festuca (Festuca elatior Schreb.) e trevo branco (Trifolium repens L.). De 1978 a 1984 a área permaneceu sem adubação e sem roçada, somente sendo pastejada. Em 1984 foi roçada, gradeada, recebeu a aplicação de 3 t/ha de calcário dolomítico, quando foi semeado trevo branco e trevo vermelho (T. pratense L.). A partir de 1984, foram aplicados de 2 a 3 t/ha de calcário dolomítico na superfície da pastagem (sem revolvimento do solo) a cada 4 ou 5 anos e realizadas adubações anuais à base de $200 \mathrm{~kg} / \mathrm{ha}$ das fórmulas 10-30-10 ou 5-30-15. Nos últimos três anos (1995-97), a adubação de manutenção foi reduzida para $100 \mathrm{~kg} / \mathrm{ha} /$ ano da fórmula 5-30-15.

A área com sete anos de melhoramento do campo nativo (CNM 7 anos), em 1990, recebeu preparo superficial do solo com grade niveladora a uma profundidade média de 4 a $5 \mathrm{~cm}$, aplicação superficial de calcário e fertilizantes, e introdução de trevo vesiculoso (Trifolium vesiculosum Savi), que não se estabeleceu satisfatoriamente e foi substituído por trevo branco e trevo vermelho a partir de 1991. Quanto à correção e à adubação do solo, foi adotado o mesmo critério do CNM 24 anos. As características químicas do solo, na camada de 0 a $10 \mathrm{~cm}$, foram semelhantes entre os tratamentos queimado e sem queima com ou sem roçada, que apresentaram menor fertilidade, enquanto os melhorados não diferiram e tiveram maiores níveis de fertilidade. Os valores das variáveis químicas de solo foram, respectivamente, para tratamentos sem e com melhoramento: 4,7 e 5,5 de $\mathrm{pH}\left(\mathrm{H}_{2} \mathrm{O}\right) ; 3,6$ e 0,4 de $\mathrm{Al}$ troc. (cmolc/L); 1,3 e 6,0 de Ca troc. (cmolc/L); 1,0 e 4,0 de Mg troc. (cmolc/L); 146,3 e 134, 1 de K (mg/L); 1,4 e 4,9 de P (mg.L); 6, 0 e $6,3 \%$ de MO (Heringer, 2000).

Nas áreas sem queima, o pastejo adotado, desde o início da aplicação dos tratamentos, foi o rotativo, baseado na oferta de forragem com o período de pastejo variável em função da quantidade de forragem disponível. Os piquetes melhorados, após realização de adubação e roçada em fevereiro, foram diferidos até $1^{\mathrm{o}}$ de junho. Durante os quatro meses de inverno (junho a setembro), a pastagem foi utilizada como "banco de proteína", com pastejo diário de 30 minutos para todos os animais. A área do tratamento queimado permaneceu com lotação contínua durante todo o ano. As avaliações da pastagem coincidem temporalmente com os períodos de pastejo e descanso da pastagem.

Os sítios escolhidos para avaliação da vegetação foram constituídos por áreas de 10 x 30 m, situados numa encosta de cada piquete, cuja situação é a mais representativa do relevo da região. Em cada sítio foram locadas três gaiolas de exclusão ao pastejo.

A avaliação da vegetação ocorreu ao longo de um ano (de setembro/1997 a setembro/1998), e as amostras foram coletadas dentro das gaiolas de exclusão ao pastejo, com área basal de $0,72 \mathrm{~m}^{2}$. Após cada avaliação, as gaiolas foram removidas para novo local, representativo da condição do sítio, a cada início de estação, após uniformização da vegetação, onde essas seriam locadas. O corte de uniformização foi feito a uma altura de $5 \mathrm{~cm}$ acima do nível do solo, sendo o material cortado, removido da área. Essa altura de corte foi mantida ao longo das avaliações, em função do objetivo de avaliar o rebrote da forragem cortada a cada 45 dias.

Omaterialcortado foi colhidode um quadradode $0,25 \mathrm{~m}^{2}$ e acondicionado em sacos de polietileno. No laboratório, as amostras da pastagem foram separadas, descartando-se da amostra o material senescente e espécies indesejáveis (principalmente dos gêneros Bacharis e Eryngium), o que redundou na matéria seca da forragem verde (MSFV), que, após seca, foi expressa em $\mathrm{kg} / \mathrm{ha}$.

Após o corte em cada gaiola, foi recolhido o material morto desprendido das plantas junto à superfície do solo. Após seco em estufa, o peso do material morto foi expresso em $\mathrm{kg} / \mathrm{ha}$ de MS.

A metodologia estatística incluiuanálise de variância, e as diferenças e/ou interações significativas, em nível de $5 \%$, ensejaram a aplicação do teste de WallerDuncan para os efeitos principais e o teste $t$ de Student para as interações. Para as variáveis medidas ao longo do tempo, o erro utilizado foi o da variação temporal dos tratamentos. Utilizou-se um nível de diferença estatística maior (10\%) durante a estação fria, considerando-se a importância da acumulação de forragem no período crítico de crescimento da pastagem natural, já que, em função das grandes acumulações de forragem na primavera e verão, o valor para apontar diferença significativa aumentou consideravelmente. 


\section{Resultados e Discussão}

Os sistemas de manejo interferiram acentuadamente na produção de forragem, havendo interação $(\mathrm{P}<0,05)$ entre tratamentos e estações do ano (Figura 1). A produção de forragem dos tratamentos melhorados teve comportamento similar ao do tratamento sem queima e sem roçada na primavera e verão, tendo sido inferior no queimado e intermediário no tratamento sem queima e roçado. A produção de forragem não diferiu entre primavera e verão, à exceção do CNM 7 anos, onde a produção de verão foi superior à da primavera $(\mathrm{P}<0,05)$. No outono $\mathrm{e}$ inverno, a acumulação de forragem foi menor, destacando-se a produção do sem queima e sem roçada no outono e no inverno do CNM 24 anos, enquanto na área queimada foi inferior e intermediária nos demais tratamentos $(\mathrm{P}<0,10)$.

A alta produção anual de forragem no tratamento sem queima e sem roçada, perfazendo $9.555 \mathrm{~kg} / \mathrm{ha}$ de MSFV deve-se, sobretudo, a predominância e contribuição abundante de espécies de hábito ereto (destacando-se Sorghastrum spp.), que apresentaram alta freqüência naquele tratamento. A área sob queima foi menos produtiva ao longo de todas as estações do ano, totalizando um acúmulo anual de $3.665 \mathrm{~kg} / \mathrm{ha}$ de MSFV. O período de condução desse trabalho correspondeu ao ano seguinte ao da queima, pois a área foi queimada em 1996, e no final do inverno de 1998, seria queimada novamente. Isso significa que a área teve um ano de descanso, sem queima, que poderia auxiliar na sua recuperação. Embora o período de avaliação caracterizou-se como um ano de alta precipitação, superior a média histórica, a área sob queima apresentou estabilidade, com menores flutuações na produção de forragem ao longo da estação de crescimento.

A destacada produção anual de forragem dos tratamentos melhorados, atingindo 9.537 e $9.148 \mathrm{~kg} / \mathrm{ha}$ de MSFV, respectivamente no CNM 24 e CNM 7 anos, deve-se, sobretudo, ao crescimento de espécies nativas, que responderam bem ao aumento na fertilidade do solo e à nova dinâmica dos nutrientes no solo. O Paspalum notatum biotipos André da Rocha e Comum apresentou contribuição majoritária nessas áreas, e tem demonstrado potencial de produção similar aos melhores materiais exóticos, conforme exemplo citado por Nabinger (1998), podendo atingir taxa de acúmulo diário em torno de $150 \mathrm{~kg} / \mathrm{ha} / \mathrm{dia}$ de $\mathrm{MS}$, quando não há limitações hídricas e nutricionais. Daí a

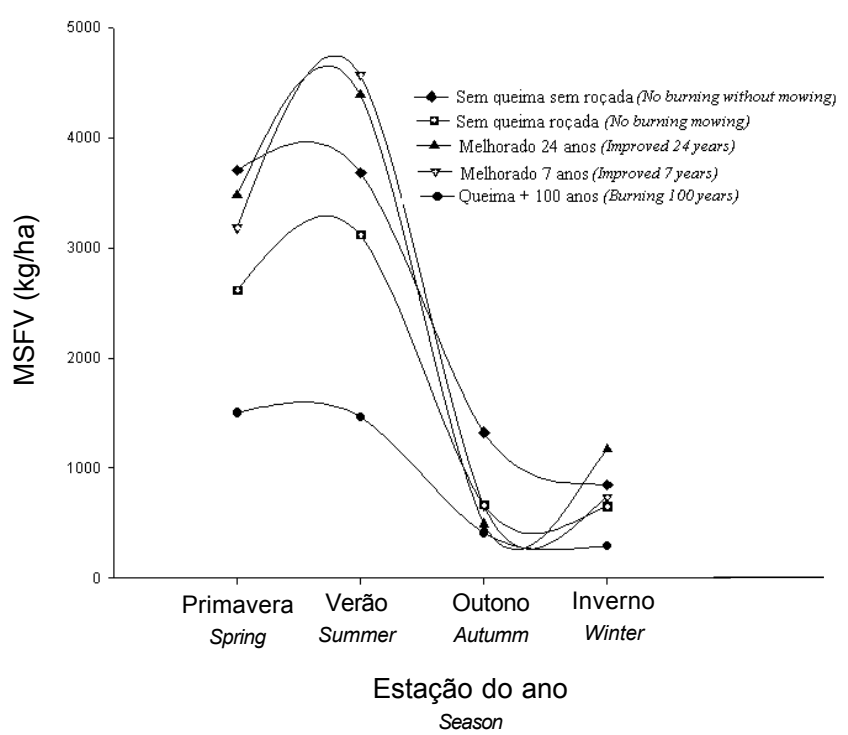

Figura 1 - Produção média estacional de matéria seca da foragem verde (MSFV) em pastagem nativa sob distintos manejos. André da Rocha-RS, 1998.

Figure 1 - Average seasonal production of green forage dry matter in native pasture under distinct management pratices. André da Rocha-RS, 1998.

importância de valorizar esses materiais nativos, que apresentam a vantagem de já estarem estabelecidos e em equilíbrio com o ambiente (Nabinger, 1998).

A produção de forragem do tratamento sem queima e roçado foi alta em relação às produções de forragem usualmente obtidas em outros ambientes e em sistemas de manejo onde também não há o emprego de fogo. A produção de $7.049 \mathrm{~kg} / \mathrm{ha} /$ ano de MSFV na área sem queima e roçada está acima dos registros de produção anual em pastagens nativas não adubadas do Rio Grande do Sul, que é de 2.500 a $6.000 \mathrm{~kg} / \mathrm{ha}$ de MS (Moojen, 1991). Em região similar a essa, no planalto catarinense, Rosa (1998) observou produção média de $7.150 \mathrm{~kg} /$ ha de MS, no período de outubro a abril, para os ecotipos Guaíba e São Joaquim de Paspalum notatum, cuja espécie contribui com mais de $50 \%$ da forragem acumulada no tratamento sem queima e roçado.

Os resultados obtidos neste trabalho, em área com histórico continuado de queimadas, contestam a maioria dos resultados de pesquisa obtidos no Brasil e também em outros ambientes, muitos deles relacionados a respostas de curto prazo. A justificativa para maiores produções de forragem em áreas queimadas (Daubenmire, 1968), seria decorrente da maior oferta de nutrientes e correção do solo pelas cinzas, redução na competição das espécies invasoras, aumento na diversidade florística da pastagem e 
através do desenvolvimento de plantas mais eficientes. Contrariamente, neste trabalho, verificou-se que a queima sistemática e contínua reduziu drasticamente a produção de forragem. Entre os fatores levantados para essa resposta estão o menor retorno de material morto, cobertura e água no solo; menor teor de bases e maior acidez potencial; além de maior freqüência de espécies pouco produtivas na área queimada. Produções inferiores de forragem também foram observadas por Castilhos \& Jacques (1984) em áreas queimadas.

A distribuição anual heterogênea da produção de forragem é característica das pastagens naturais do sul do Brasil, onde há predomínio na flora de espécies de crescimento estival. Nos Campos de Cima da Serra, porém, a distribuição é ainda mais heterogênea quando comparado à Depressão Central do Estado (Moojen, 1991), em função da ocorrência de invernos mais rigorosos naquela região, e pela maior freqüência de estiagens na Depressão Central, que reduz o potencial produtivo da vegetação durante a estação favorável de crescimento.

Quanto ao material morto (Figura 2), os dados mostram uma quantidade existente na superfície do solo superior no tratamento sem queima e sem roçada $(\mathrm{P}<0,05)$. Isto pode ser explicado tanto em função do maior retorno de material morto, como pela menor taxa de mineralização dos restos de vegetação (material envelhecido e rejeitado no pastejo) nesse tratamento.

A qualidade da forragem dos tratamentos, considerando-se somente gramíneas e leguminosas verdes, foi similar entre os tratamentos melhorados e o roçado, com $14 \%$ de PB e 56,1\% de DIVMO, e entre o tratamento sem queima e sem roçada e o queimado, com $10 \%$ de PB e $43,8 \%$ de DIVMO (Heringer, 2000), influenciando a velocidade de reciclagem do material morto. Em função da grande freqüência de espécies fibrosas no tratamento sem queima e sem roçada, ocorreu maior estabilidade da fração material morto na pastagem. Também, na área queimada, a vegetação apresentava aspecto semelhante, indicando que a mineralização dos restos vegetais é mais lenta, redundando em menor taxa de degradação do material morto. Como no tratamento sem queima e sem roçada a pastagem foi utilizada menos intensamente, sendo deixada como reserva de pasto "em pé" no outono e início do inverno, permitiuse maior disponibilidade de matéria seca na pastagem, também por conta da maior produção e predominância de Sorghastrum sp. Assim, há maior

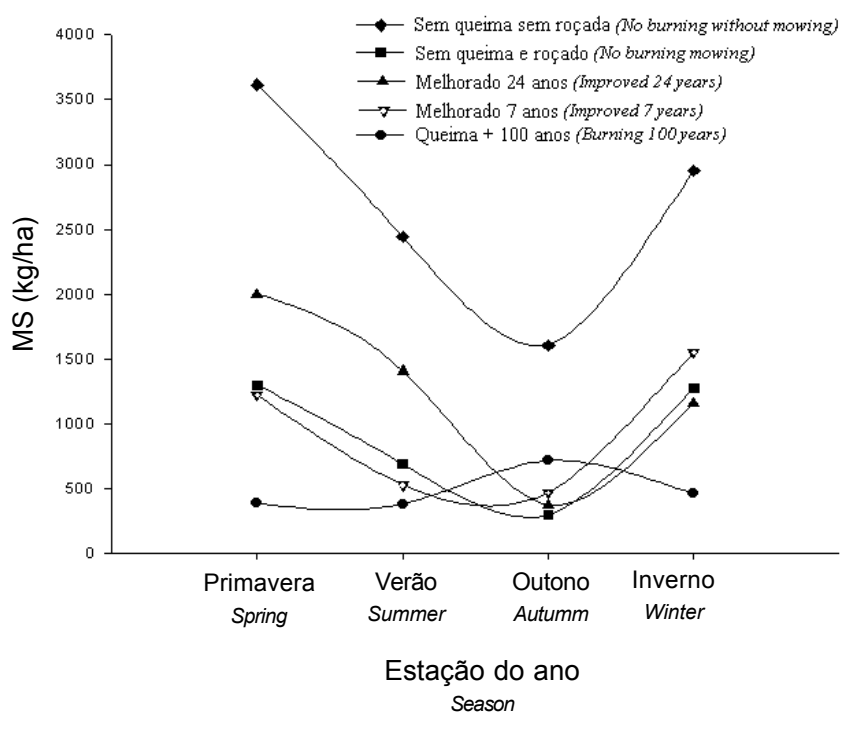

Figura 2 - Material morto presente na superfície do solo em pastagem nativa sob distintos manejos. André da Rocha-RS, 1998.

Figure 2 - Litter present on soil surface in native pasture under distinct management sustems. André da Rocha-RS, 1998.

acúmulo de material morto neste tratamento, o qual tende a permanecer mais tempo na superfície até que ocorra sua mineralização. A disponibilidade de $\mathrm{N}$ e atividade microbiana também podem contribuir para menor mobilização da matéria orgânica nesse tratamento (Luizão et al., 1993; Mary et al., 1996).

Observações visuais feitas nas áreas melhoradas e roçada, entre os períodos de amostragem, indicam uma grande flutuação no material morto presente na superfície, devido a uma alta taxa de "desaparecimento" (sobretudo quando havia precipitação e temperatura maiores), demonstrando que há uma reciclagem mais rápida desses materiais. Isto é confirmado por Mary et al. (1996) que comentam que a matéria orgânica decompõe-se mais rapidamente em solos corrigidos, ou com quantidades maiores de bases, do que naqueles ácidos.

A queima apresentou quantidade média estacional inferior a $500 \mathrm{~kg} / \mathrm{ha}$ de MS de material morto na superfície. O pastejo mais intenso e a lavagem dos restos vegetais presentes na superfície do solo estão entre os principais fatores determinantes da menor quantidade de material morto nesse tratamento.

As flutuações no material morto presente na superfície do solo (Figura 2) apontam para uma quantidade superior na primavera $(1.705 \mathrm{~kg} / \mathrm{ha} \mathrm{de}$ $\mathrm{MS})$, seguida de inverno, verão e outono $(\mathrm{P}<0,05)$, respectivamente, com 1.479, 1.090 , e $691 \mathrm{~kg} / \mathrm{ha}$ de MS, como média de todos tratamentos. Essas avalia- 
ções foram feitas na metade e final de cada estação e representam valores médios para o período. O material morto presente na superfície é dependente do crescimento e eficiência de utilização da pastagem. No outono há menor crescimento das plantas e, com isso, a MS disponível da pastagem é baixa e, conseqüentemente, os animais podem consumir maior quantidade de material morto, reduzindo a quantidade desse componente na superfície do solo.

Na Figura 2, observa-se que, enquanto há redução no volume de material morto em todos tratamentos sem queima, durante o outono, na área queimada, verifica-se a maior quantidade desse material presente na superfície do solo ao longo do ano. Esse comportamento é exclusivo da vegetação da área queimada em que, ao final do verão, somente mantém-se a base de plantas viva e, assim, permanece até a aplicação do fogo, no final do inverno, quando então inicia o rebrote. Isso determina maior rejeição ao pastejo e retorno de material morto na superfície do solo durante o outono.

\section{Conclusões}

Os distintos manejos da pastagem natural por longo período são responsáveis pelas diferentes estruturas da vegetação. Os sistemas de manejo sem queima, com ou sem roçada, são mais produtivos e preservam melhor o solo em função da cobertura por plantas e material morto, e reciclagem de nutrientes via material morto.

O melhoramento da pastagem através da correção e adubação do solo e introdução de leguminosas aumenta a produção de forragem e a quantidade de material morto que retorna ao solo.

A queima de pastagens naturais sul brasileiras, como prática de manejo rotineira, reduz o potencial de produção de forragem e de material morto.

\section{Literatura Citada}

BARRETO, I.L.; VICENZI, M.L.; NABINGER, C. Melhoramento e renovação de pastagens. In: SIMPÓSIO SOBRE MANEJO DE PASTAGEM, 5., 1978, Piracicaba. Anais... Piracicaba: Cargill, 1978. p. 28-63.

BURKART, A. Evolucion of grasses and grasslands in South America. Taxon, v.24, p.53-66, 1975.

CASTILHOS, Z.M.S.; JACQUES, A.V.A. Produção e qualidade de uma pastagem natural submetida a tratamentos de introdução de trevo vesiculoso cv. Yuchi (Trifolium vesiculosum Savi), ceifa e queima. Porto Alegre: Secretaria da Agricultura Estado Rio Grande do Sul, v.11, p.65-112, 1984.

DAMÉ, P.R.; QUADROS, F.L.F.; KERSTING, C.E.B. et al. Efeitos da queima seguida de pastejo ou diferimento sobre a produção, qualidade, cobertura do solo e sistema radicular de uma pastagem. Ciência Rural, v.27, n.1, p.133-137, 1997.

DAUBENMIRE, R. Ecology of fire in grasslands. Advances in Ecological Research, v.5, p.209-266, 1968.

EMPRESA BRASILEIRA DE PESQUISA AGROPECUÁRIA EMBRAPA. Centro Nacional de Pesquisa de Solos. Sistema brasileiro de classificação de solos. Brasília, 1999. 412p.

GIOVANNINI, G.; LUCCHESI, S. Modifications induced in soil physico-chemical parameters by experimental fires at different intensities. Soil Science, v.162, n.7, p.479-486, 1997.

GIOVANNINI, G.; LUCCHESI, S.; GIACHETTI, M. Effect of heating on some chemical parameters related to soil fertility and plant growth. Soil Science, v.149, n.6, p.344-350, 1990.

GIRARDI-DEIRO, A.M.; MOTA, A.F.; GONÇALVES, J.O.N. Efeito do corte de plantas lenhosas sobre o estrato herbáceo da vegetação da Serra do Sudeste, RS, Brasil. Pesquisa Agropecuária Brasileira, v.29, n.12, p.1823-1832, 1994.

HERINGER, I. Efeitos do fogo por longo período e de alternativas de manejo sobre o solo e a vegetação de uma pastagem natural. Porto Alegre: Universidade Federal do Rio Grande do Sul, 2000. 193p. Tese (Doutorado em Zootecnia) - Universidade Federal do Rio Grande do Sul, 2000.

HESTER, J.W.; THUROW, T.L.; TAYLOR Jr., C.A. Hydrologic characteristics of vegetation types as affected by prescribed burning. Journal of Range Management, v.50, n.2, p.199-204, 1997.

KAUFFMAN, J.; CUMMINGS, D.L.; WARD, D.E. Relationships of fire, biomass and nutrient dynamics along a vegetation gradient in the Brasilian Cerrado. Journal Ecology, v.82, p.519-531, 1994.

LUIZAO, R.C.C.; BONDE, T.A.; ROSSWALL, T. Seasonal variation of soil microbial biomass- the effects of clearfelling a tropical rainforest and establisment of pasture in the Central Amazon. Soil Biology and Biochemistry, v.24, p.805-813, 1993.

MARY, B.; RECOUS, S.; DARWIS, D. et al. Interactions between decomposition of plant residues and nitrogen cycling in soil. Plant and Soil, v.181, p.71-82, 1996.

MOOJEN, E.L. Dinâmica e potencial produtivo de uma pastagem natural do Rio Grande do Sul submetida a pressões de pastejo, épocas de diferimento e níveis de adubação. Porto Alegre: Universidade Federal do Rio Grande do Sul, 1991. 172p. Tese (Doutorado em Zootecnia) Universidade Federal do Rio Grande do Sul, 1991.

NABINGER, C. Técnicas de melhoramento de pastagens naturais no Rio Grande do Sul. In: SEMINÁRIO SOBRE PASTAGENS: de que pastagens necessitamos, 1980, Porto Alegre. Anais... Porto Alegre: FARSUL, 1980. p.28-58.

NABINGER, C. Princípios de manejo e produtividade de pastagens: In: CICLO DE PALESTRAS EM PRODUÇÃO E MANEJO DE BOVINOS DE CORTE, 3., 1998, Porto Alegre. Anais ... Porto Alegre: ULBRA, 1998. p. 54-107.

PILLAR, V.P.; QUADROS, F.L.F. Grassland-forest boundaries in southern Brazil. Coenoses, v.12, v.2/3, p.119-126, 1997.

ROSA, J.L. Produção de forragem de gramíneas perenes de estação quente no Planalto Catarinense. In: REUNIÃO DO GRUPO TÉCNICO EM FORRAGEIRAS DO CONE-SUL -ZONA CAMPOS, 17., 1998, Lages. Anais... Lages: Epagri/ UDESC, 1998. p. 110.

SILVA, J.L.S.; JACQUES, A.V.A. Disponibilidade de forragem de uma pastagem natural, sobressemeada com leguminosas perenes de estação quente. Revista da Sociedade Brasileira de Zootecnia, v.22, n.6, p.920-929, 1993.

Recebido em: 17/05/01 Aceito em: 03/12/01

R. Bras. Zootec., v.31, n.2, p.599-604, 2002 